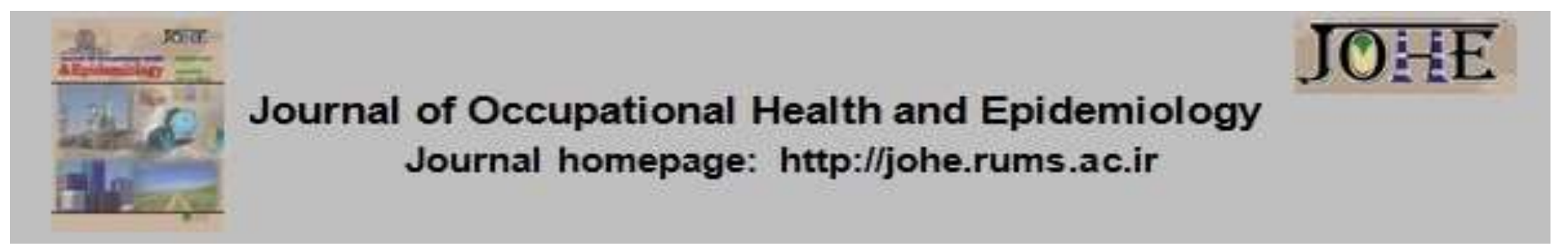

\title{
The hazards of pedestrian mobile-phone use when crossing signalized intersections, Iran (2017); an observational study
}

\author{
Alireza Khosromehr ${ }^{1}$, Seyed Rasoul Davoodi ${ }^{*}$ \\ 1- Department of Civil Engineering, Faculty of Engineering, Golestan University, Gorgan, Iran.
}

Article Info

* Corresponding author:

Seyed Rasoul Davoodi,

E-mail:

davoodi76ir@gmail.com

Article history

Received: Jan, 2019

Accepted: May, 2019

$10.29252 / j 0 h e .8 .2 .65$

Print ISSN: 2251-8096 Online ISSN: 2252-0902

Peer review under responsibility of Journal of Occupational Health and Epidemiology
Citation: Khosromehr A, Davoodi SR. The hazards of pedestrian mobile-phone use when crossing signalized intersections, Iran (2017); an observational study. JOHE 2019; 8(2):65-75.

\begin{abstract}
Background: Distracted walking is a major cause of pedestrian fatalities. Along with the expansion and popularity of mobile phones, their impacts on pedestrian safety, especially when crossing urban intersections have attracted a lot of attention. The purpose of this study is to evaluate the effects of mobile-phone use on pedestrians' crossing behavior when passing signalized intersections.

Materials and Methods: An observational study was conducted to compare the behavior of pedestrians using mobile phones (the reference group) with non-mobile phone pedestrians (the time-matched control group and the demographic-matched control group) crossing signalized intersections in 2017. For this purpose, the demographic information and walking behaviors of 513 pedestrians were observed. Furthermore, a binary logistic regression model was used to predict risky behaviors.

Results: Using mobile phones has a direct impact on the unsafe behavior of pedestrians crossing signalized intersections. Mobile-phone users showed significantly less safe behavior ( 14.6 times) than non-mobile phone users $(p<0.001)$. Using mobile phones to talk had the greatest impact on the vulnerable behavior of pedestrians $(p<0.001)$. SMS conversations and listening to music were in the next positions, respectively ( $p=0.283$ ).

Conclusions: Using mobile phones can often lead to the carelessness of pedestrians and their exposure to the possible risk of pedestrian-vehicle crashes. Applying the findings of the present research requires effective technologies and strategies to prevent the use of mobile phones by pedestrians at signalized intersections.
\end{abstract}

Keywords: Pedestrians, Distraction, Mobile Phone, Safety.

\section{Introduction}

Like other transport modes, walking is a transport mode, which involves the safety concerns of pedestrians and vehicle confrontation $(1,2)$. US pedestrian-vehicle crashes in 2005 accounted for $11 \%$ of the total traffic fatalities of the country, while the number increased to $15 \%$ of the total traffic deaths in 2014 (3). Fortunately, according to a World Health Organization's report, the average traffic fatalities have dropped in recent years in Iran, yet they have still a larger share of driving-related fatalities than most of other countries in the world. Based on this report, $23 \%$ of all traffic deaths belonged to pedestrian fatalities in 2013 (4). In Iran, pedestrian offensive into the street is one of the major causes of accidents. However, according to chapter 215 of the Road Traffic Code, which lists the nine-part duties of pedestrians, pedestrians must pass in the widthwise direction only on pedestrian crossings and passageways.

Distraction means the process of diverting the attention of individuals from a subject that is restricted or blocked from receiving information (57). 'Pedestrian distraction", according to Tehran Municipality's Traffic Police Deputy, is the third factor in the intensification of Tehran's (capital of Iran) traffic load, in which pedestrians play a key role. In addition, distraction contributes to a large number of pedestrian-vehicle collisions, fatalities, 
and injuries (1, 2, 7, 8). Distraction potentially increases the risk of vehicle-pedestrian crashes (9). According to NHTSA's reports, 3,179 people were killed and approximately 431,000 others were injured in distraction-affected motor vehicle crashes in 2014 (10). In recent years, the use of mobile phones has been distracting pedestrians and potentially exposing them at the risk of crashes with motor vehicles more than ever (8). Pedestrians and drivers are more distracted all around the world with an increase in the use of electronic information and entertainment devices (11). In the united states, the frequency of mobile phone-related injuries has increased over the years 2000-2011 both at home and outdoors (12).

Using a mobile phone distracts attention even during a simple task that requires few cognitive resources (13). Hyman et al (13) found out that pedestrians talking on their mobile phone usually walked slower, were less likely to acknowledge other people, and changed directions more frequently than individuals in other conditions, such as those with no electronics, music player users, and pairs. They also realized that such users were less likely to notice abnormal movements and objects, such as a unicycling clown (13) or money hanging from tree branches along their way (14). Numerous studies have examined the effects of mobile phones on drivers, while only a few ones have assessed the effects of using mobile phones on pedestrian safety behavior (15).

In an observational research, Bungum et al (2005) studied the relationship between distracted walking and the usual precautionary behaviors of 866 pedestrians as they passed an intersection on a busy street near a famous university in Las Vegas. They reported a negative correlation between pedestrian distraction and their caution behavior in the street. During the experiment, distracted pedestrians showed less precautionary behavior than those not distracted (16).

Hatfield \& Murphy (2007) also observed and recorded the behaviors of 546 pedestrians at both signalized intersections and at intersections with no traffic light. They found out that pedestrians talking on their mobile phones showed less caution behavior than the control group. They concluded that the lack of caution behavior among pedestrians was significantly due to the cognitive needs involved in pedestrian conversation. They also realized that people talking on their mobile phones walked in the street slower than the less distracted ones; in addition, they noticed that using a mobile phone while crossing the street led to some unsafe behaviors, which were largely gender-specific (17). Nasar et al (2008) conducted two distinct studies to cause pedestrian distraction through the use of mobile phones. In the first experiment, 60 participants walking along the designated route were divided into two halves, including those who were talking on their mobile phones and the others carrying their mobile phones while waiting for a call that never occurred (these 30 individuals were not using a mobile phone). By comparing the performance of the two groups in reminding the things located on their way, it was found out that pedestrians in the first group remembered less than the other group. In the second study, three observers recorded the behaviors of pedestrians with/without a mobile phone (iPod) while crossing three roads. The mobile-phone group behaved by far less safely than other pedestrians in traffic. Like drivers, such pedestrians always face cognitive distraction caused by the reduced level of awareness and increased rate of unhealthy behavior, which put them at the risk of pedestrianvehicle collisions and being victimized (18).

In another article, the effects of distraction caused by technology and social distractors were examined on the precautionary behavior and crossing time of pedestrians. Pedestrians $(n=1102)$ who were at the risk of crossing 20 intersections or crossroads within the specified time intervals of 1-3 hours were studied, with their crossing behaviors recorded by the observers. Nearly one third of them (29.8\%) were distracted while crossing the street. SMS conversations also resulted in a 1.87-second longer walking time $(18.0 \%)$ required for crossing the intersection than in the people not distracted. Those listening to music crossed the intersection more than half a second (0.54) faster than the control group. Regarding gender, the females were slower than the males; moreover, the older the people were, the slower they passed the street. The results also showed that disruptive behaviors, age, gender, and social groups had no significant correlation with the pedestrians' habit of passing crossings or their obedience to traffic lights (19).

Using observation as a method of data collection, Antic et al [15] examined the crossing behaviors of 1,194 pedestrians crossing non-signalized intersections. The results indicated that pedestrians using a mobile phone while crossing the street showed less safe behavior than those who did not use one. Talking on mobile phones had the greatest impact on the hazardous behavior of the pedestrians; sending messages or viewing the content and information on the phone screen as well as listening to music were the second and third most effective factors, respectively. In addition, they concluded that talking on a mobile phone, text messaging, viewing the content and information on the phone screen, and listening to music all had 
different impacts on the cognitive, visual, and physical abilities of the pedestrians.

The mobile-phone penetration rate in Iran is highest (78\%) among the Middle East and North African countries (with a mean of $63 \%$ ), being higher than the global average as well (67\%) (20). However, few studies have been conducted in developing countries (like Iran) on the dangers of mobile-phone use by pedestrians while crossing the street. The purpose of this study is to assess the effects of mobile-phone use on pedestrians' crossing behavior while passing signalized intersections.

\section{Materials and Methods}

This observational study assessed pedestrian mobile-phone use at Gorgan intersections in 2017. Based on the research nature, the data collection method was direct observation. This method is particularly effective in assessing traffic safety in places where there is sufficient information (15). Observation, as made by a camera, can be either direct or indirect. In this study, observers were familiarized with the operational definition of the behaviors and characteristics to be observed and recorded.

Two observers recorded the demographic characteristics and crossing behavior of the pedestrians. In order to avoid the possibility of subjective pedestrian selection and increase the quality of data collection, a randomized approach was adopted for each observer to record the behaviors of all those pedestrians using their personal mobile phones and music players, regardless of the method of conversation, i.e. on a mobile phone (whether a mobile phone or ear buds) or sending messages (SMS, internet, mobile software, and viewing details on the mobile phone screen). For each case, the observer recorded the name of the first person crossing the same passage in the same direction, who did not use a mobile phone or a personal music player (the timedmatched control group). Next, the observer recorded the behavior of the homogenous pedestrians who were of about the same age with the first pedestrian, who did not use cell phones and personal music players (the demographic-matched control group). Thus, the observational data were collected in three sets.

At each intersection, two observers recorded the behavior of all pedestrians who met the selection criteria. Each observer looked for 15 minutes at one direction of the intersection and then looked at the opposite side. Since there were eight pedestrian crossing directions for each intersection, regardless of the diagonal paths, it took one hour to cover all eight directions at 15-minute intervals. The observers had already been trained by the researchers to learn how to register and classify the pedestrians' data. To provide examples for the better understanding of the assigned tasks, the researchers also used video clips recorded at some intersections to explain major recording issues.

After the initial training of the observers, a pilot study was conducted at two sites from among the study sites for data collection purposes. Next, two trained observers recorded the pedestrians' behavioral and demographic information individually; their collected information was then compared, and finally, the inter-observer reliability (the Cohen's kappa coefficient) was calculated. The Cohen's kappa coefficient $(\mathrm{K})$ is a statistic which measures the interrater agreement for qualitative (categorical) items (21). A 90\% inter-observer validity and accuracy rate was established for all demographic variables (age, gender and the way of using the mobile phone) and all crossing behavior variables (looking at the traffic before moving, waiting for the traffic to stop before crossing, crossing at the marked pedestrian crossings, and looking at the traffic while crossing the intersection) recorded by the two observers.

Three residential-commercial urban areas were selected in terms of socio-economic conditions (low, medium, and high status, given their housing and land prices) in the city of Gorgan (Iran) with the population of 450,541 . In each area, a signalized intersection was selected (four-leg intersections with two traffic lanes in each direction, with a medium traffic load and pedestrian volume). According to the Law on Road Traffic, the speed limit in these inhabited areas in Iran is $60 \mathrm{~km} / \mathrm{h}$. In addition, the rates of the traffic movement of trucks and buses were very low (less than 4 per hour), and there was no pedestrian light at the chosen intersections. The selection criterion chosen by the researchers included those intersections with the highest pedestrian flow based on the data achieved from the Traffic Department of Gorgan Municipality so that the highest efficiency of the data collection procedure would be obtained. The data were collected on a workday (Wednesday) and on a weekend day (Friday). This study was conducted in April when days were sunny. Data collection was conducted every day at three two-hour time intervals of morning (from 08:00 a.m. to 10:00 a.m.), noon (from 12:00 p.m. to 02:00 p.m.), and afternoon (from 04:00 to 6:00 p.m.). These periods were chosen to increase the traffic flow of the pedestrians.

An observation sheet was prepared to record two types of information, including the demographic and crossing behaviors of the pedestrians. Demographic data, including gender and age 
groups $(\leq 18,19-24,25-44,45-64,>64)$ were utilized.

In terms of the crossing behavior, the observers recorded their crossing direction, looking at the traffic before crossing (yes/no), waiting for the traffic to stop before crossing (yes/no), crossing at the marked pedestrian crossings (yes/no), and looking at the traffic when crossing the intersection (yes/no). Crossing at the marked pedestrian crossings means that the pedestrians did not walk more than one step out of the pedestrian crossings. Looking at the traffic before crossing the intersection means that the observers viewed at least one pedestrian overpassing in front of the traffic junction before stepping into the street. Looking at the traffic while crossing the intersection means that the pedestrian's head moved alongside the street to the left and then to the right, each time to control the traffic flow.

The observers recorded both pedestrians who did not use mobile phones or other electronic devices as well as the users of mobile phones and other electronic devices, in addition to the way they used them while crossing the intersection. The way of using mobile phones included mobile phone conversations (via mobile phone or hands-free calls), message conversations (SMS, internet, mobile phone apps, or viewing details on the mobile phone screen), and listening to music (via headphones).

For data analysis, all data were entered into Microsoft Office Excel 2016 and SPSS Statistics 23.0. In addition, descriptive and analytic methods were used. The mean frequency (Me), the absolute frequency $(n)$, and the relative frequency (\%) were used to present descriptive statistics; besides, a Chi-square test was used to examine the effects of different factors (gender, age, and mobile phone use). The sign test was also used to compare the significance of the difference between the paired groups (the reference group vs the demographicmatched control group and the reference group vs the time-matched control group). In addition, the binary logistic regression was used to predict the unsafe behavior of pedestrians crossing the intersection. Gender, age, and mobile phone use were also considered as predictor variables. The threshold of statistical significance (a) was considered at 0.05 .

Pedestrian distractions were divided into listening to music (headphones), talking on mobile phones (via a mobile phone or hands-free calls), and message conversations (SMS, internet, mobile apps, or viewing cell phone details). The youngest age group $(\leq 18)$ was considered as the reference age group, for past studies have shown that younger pedestrians exhibit riskier behavior than older ones, being more likely to experience a pedestrian-vehicle crash (22-24).

Binary logistic regression models were employed to predict the unsafe behavior of the pedestrians. In these models, the safety variable (safe or unsafe behavior), the multiple variable, and explanatory variables (gender, age, and mobile phone use) were the categorized factors used to predict the response variable. Different types of the mentioned models included:

- The compound model of unsafe behavior

- The model of not looking at the traffic before crossing signalized intersections

- The model of not looking at the traffic when crossing the signalized intersection

- The model of not crossing at the marked pedestrian crossings

\section{Results}

The behaviors of 513 pedestrians, including 308 men and 205 women, were observed and recorded. For this purpose, 191 (37.2\%) people in the low urban economic and social standing, 210 (40.9\%) people in the medium urban economic and social standing, and 112 (21.9\%) people in the high urban economic and social standing were analyzed. In fact, $312(60.8 \%)$ people were observed on workdays (Wednesdays) and 201 (39.2\%) people were observed on weekends (Fridays). To be more exact, $105(20.5 \%)$ people were talking on mobile phones, $52(10.1 \%)$ people were involved in SMS conversations or other types of activities associated with texting on mobile phones, and 14 (2.7\%) people were listening to music. Due to the absence of pedestrian signals at the signalized intersections of the city, there was little interaction among pedestrians in terms of obeying the red traffic light and refraining from crossing the traffic to pass the street ( $n=490$ people), so the 'waiting for the traffic to stop before crossing' behavior was removed for all calculations. The details and frequency of the observed individuals are shown in Table 1. 
Table 1: Sample description and frequency table $(n=513)$

\begin{tabular}{|c|c|c|c|}
\hline Characteristic & & $\mathbf{N}$ & $\%$ \\
\hline \multirow[b]{2}{*}{ Gender } & Male & 308 & 60 \\
\hline & Female & 205 & 40 \\
\hline \multirow{5}{*}{ Age } & $<18$ & 31 & 6 \\
\hline & 18-24 & 81 & 15.8 \\
\hline & $25-44$ & 272 & 53 \\
\hline & $45-64$ & 116 & 22.6 \\
\hline & $65<$ & 13 & 2.5 \\
\hline \multirow{4}{*}{ Using } & Talking on the phone & 105 & 20.5 \\
\hline & Texting & 52 & 10.1 \\
\hline & Listening to music & 14 & 2.7 \\
\hline & Not using & 342 & 66.7 \\
\hline \multirow{2}{*}{ Looking at the traffic before crossing } & Yes & 346 & 67.4 \\
\hline & No & 167 & 32.6 \\
\hline \multirow{2}{*}{$\begin{array}{l}\text { Waiting for the traffic to stop before } \\
\text { crossing (traffic flow present) }\end{array}$} & Yes & 23 & 4.5 \\
\hline & No & 490 & 95.5 \\
\hline \multirow{2}{*}{ Looking at the traffic while crossing } & Yes & 360 & 70.2 \\
\hline & No & 153 & 29.8 \\
\hline \multirow{2}{*}{$\begin{array}{l}\text { Walking at the marked pedestrian } \\
\text { crossing }\end{array}$} & $\overline{Y e s}$ & 418 & 81.5 \\
\hline & No & 95 & 18.5 \\
\hline
\end{tabular}

According to the results, the highest correlation was observed between the behavior of not looking at the traffic before crossing the street and the behavior of not looking at the traffic while crossing the street $(21.1 \%)$; in other words, $21.1 \%$ of those who did not look at the traffic before passing the street did not look at the traffic while crossing the street. In addition, of those who did not walk at the marked pedestrian crossing, $9.2 \%$ and $10.1 \%$ did not look at the traffic before and while crossing the street, respectively.

To better understand the relationship among the variables (independent variables) effective in the unsafe behavior of the pedestrians while crossing the signalized intersections (the dependent variable), the Chi-square test was utilized. This test is applied to discontinuous data and evaluates the independence or dependence of both effective and influential variables logically. The test results are presented in Table 2 at the significant level of 0.05 . The occurrence of even an unsafe case of behavior by pedestrians, such as not looking at the traffic before crossing the street, not waiting for the traffic to stop before crossing, not crossing at the marked pedestrian crossings, and not looking at the traffic while crossing the street, was considered as an unsafe case of behavior of the pedestrians. The behavior of the pedestrians would be considered optimal if they exhibited all three safe behaviors of 'passing through the pedestrian crossings, as well as looking at the traffic before and when crossing the street.' The results have been presented in Table 2.

As inferred from the results presented in Table 2, gender affects the occurrence of the pedestrians' unsafe behavior $(P<0.001)$ significantly so that women have been likely to exhibit at least one case of unsafe behavior more than men. Although age had no significant effect on the unsafe behavior of the pedestrians, walking conditions were significantly correlated with their safe behavior of crossing $(P<0.001)$; likewise, those talking on their mobile phones were more likely to exhibit at least one case of unsafe behavior, with SMS users having stood in the second place. Interestingly, music listeners were less likely to display unsafe behavior than mobile users and people with no electronic device.

Table 2: The results of the correlation between unsafe behavior and the characteristics of the pedestrians at the signalized intersections, based on the Chi-square test

\begin{tabular}{|c|c|c|c|c|c|}
\hline & actor & Safe (\%) & Unsafe (\%) & P-value & $\begin{array}{c}\text { Chi-squared } \\
\text { test }\end{array}$ \\
\hline \multirow{2}{*}{ Gender } & Female & 42.9 & 57.1 & \multirow{2}{*}{$P<0.001$} & \multirow[b]{2}{*}{12.381} \\
\hline & Male & 58.8 & 41.2 & & \\
\hline \multirow{5}{*}{ Age } & $<18$ & 61.3 & 38.7 & \multirow{5}{*}{$P=0.270$} & \multirow{5}{*}{5.168} \\
\hline & 18-24 & 45.7 & 54.3 & & \\
\hline & $25-44$ & 50.7 & 49.3 & & \\
\hline & 45-64 & 56.9 & 43.1 & & \\
\hline & $>64$ & 69.2 & 30.8 & & \\
\hline \multirow{4}{*}{ Walking conditions } & Talking on the mobile phone & 10.5 & 89.5 & \multirow{4}{*}{$P<0.001$} & \multirow{4}{*}{148.320} \\
\hline & Texting & 15.4 & 84.6 & & \\
\hline & Listening to music & 78.6 & 21.4 & & \\
\hline & Not using & 69.9 & 30.1 & & \\
\hline
\end{tabular}


Using the sign test, the crossing behavior of the target group was compared with that of both timematched and demographic-matched control groups when crossing the signalized intersections. The purpose of this comparison was to investigate the effects of using mobile phones on pedestrian behavior. The results of this test are shown in Table 3.
According to the results of Table 3 , the reference groups looked significantly less than other groups at the traffic ( $p<0.001)$ before crossing the signalized intersections ( $p<0.001)$, crossed less often at the marked pedestrian crossings ( $p<0.001)$, and paid less attention to the traffic while crossing the street $(P<0.001)$.

Table 3: The frequency of unsafe behavior of mobile phone users at signalized intersections compared to that of the control groups $(n=171)$.

\begin{tabular}{|c|c|c|c|c|c|c|c|c|c|c|c|c|c|c|}
\hline \multirow{3}{*}{ Factor } & \multicolumn{7}{|c|}{$\begin{array}{l}\text { Reference group }(n=171) \text { vs demographic- } \\
\text { matched control }(n=171)\end{array}$} & \multicolumn{7}{|c|}{$\begin{array}{l}\text { Reference group }(n=398) \text { vs time-matched } \\
\text { control }(n=398)\end{array}$} \\
\hline & \multicolumn{2}{|c|}{$\begin{array}{c}\text { Reference } \\
\text { group's } \\
\text { unsafe } \\
\text { behavior } \\
(\%)\end{array}$} & \multicolumn{2}{|c|}{$\begin{array}{c}\text { Demogra } \\
\text { phic- } \\
\text { matched } \\
\text { unsafe } \\
\text { behavior }\end{array}$} & \multicolumn{2}{|c|}{ Ties } & \multirow{2}{*}{$\begin{array}{c}\text { Sign test } \\
\mathbf{Z} \\
\text { (p-value) } \\
\end{array}$} & \multicolumn{2}{|c|}{$\begin{array}{c}\text { Reference } \\
\text { group's } \\
\text { unsafe } \\
\text { behavior } \\
(\%)\end{array}$} & \multicolumn{2}{|c|}{$\begin{array}{c}\text { Time- } \\
\text { matched } \\
\text { unsafe } \\
\text { behavior }\end{array}$} & \multicolumn{2}{|c|}{ Ties } & \multirow[t]{2}{*}{$\begin{array}{c}\text { Sign test } \\
\mathbf{Z} \\
\text { (p value })\end{array}$} \\
\hline & $\mathrm{N}$ & $\%$ & $\mathrm{n}$ & $\%$ & $\mathrm{~N}$ & $\%$ & & $\mathrm{n}$ & $\%$ & $\mathrm{n}$ & $\%$ & $\mathrm{~N}$ & $\%$ & \\
\hline $\begin{array}{l}\text { Pedestrians } \\
\text { didn't look } \\
\text { at the traffic } \\
\text { before } \\
\text { crossing }\end{array}$ & 115 & 67.3 & 32 & 18.6 & 24 & 14 & $\begin{array}{l}Z=-8.843 \\
(p<0.001)\end{array}$ & 115 & 63.7 & 20 & 11.8 & 36 & 21.1 & $\begin{array}{l}Z=-8.080 \\
(p<0.001)\end{array}$ \\
\hline $\begin{array}{c}\text { Pedestrians } \\
\text { didn't look } \\
\text { at the traffic } \\
\text { while } \\
\text { crossing } \\
\end{array}$ & 109 & 63.7 & 28 & 16.3 & 34 & 19.9 & $\begin{array}{l}Z=-8.923 \\
(p<0.001)\end{array}$ & 109 & 63.7 & 16 & 9.4 & 46 & 26.9 & $\begin{array}{l}Z=-8.123 \\
(p<0.001)\end{array}$ \\
\hline $\begin{array}{l}\text { Pedestrians } \\
\text { didn't walk } \\
\text { at the } \\
\text { marked } \\
\text { pedestrian } \\
\text { crossings }\end{array}$ & 47 & 27.5 & 17 & 9.9 & 107 & 62.6 & $\begin{array}{c}Z=-1.970 \\
(p=049)\end{array}$ & 47 & 27.5 & 31 & 18.2 & 93 & 54.4 & $\begin{array}{l}Z=-3.683 \\
(p<0.001)\end{array}$ \\
\hline
\end{tabular}

In the mobile phone users (the reference group), $41 \%$ of the individuals showed at least one case of unsafe behavior, while in the demographic-matched and time-matched control groups, $14.9 \%$ and $15.2 \%$ of the individuals exhibited at least one case of unsafe behavior, respectively. In addition, it was found out that the reference group had a higher chance (about 11 times) of showing at least one case of unsafe behavior than the demographicmatched $(\mathrm{OR}=10.93)$ and time-matched control groups (OR=10.93). The final model of predicting the unsafe behavior of pedestrians has a significantly greater predictive power than that of the null model (X2 = 184.075; df = 8; $p<0.001$; pseudo $\mathrm{R} 2 \mathrm{~N}=0.402)$. The final model involved predictive parameters, such as gender, age, and mobilephone use behavior (Table 4). The chance of the females showing unsafe behavior when crossing a signalized intersection was 2.5 times higher than that of the males $(p<0.001)$. Individuals aged 18-24 had a 3.5-time higher chance of showing unsafe behavior while crossing the intersection than the reference group $(\leq 18)(p=0.049)$. The age ranges of 25-45, 64-45, and > 65 did not affect the incidence of unsafe behavior ( $p>0.05$ ). Compared to people who did not use mobile phones, people engaged in mobile phones had the 23-time higher chance of showing unsafe behavior $(p<0.001)$. Likewise, those involved in SMS conversations or viewing details on mobile phones had a significantly higher chance of showing risky behavior when crossing the intersections than those who did not use mobile phones ( $p<0.001$ ); however, listening to music had no significant effect on showing unsafe behavior by these pedestrians $(p=0.076)$. 
Table 4: The odds ratio for the predictive variables of unsafe behavior shown by pedestrians when crossing signalized intersections

\begin{tabular}{|c|c|c|c|c|c|}
\hline \multicolumn{2}{|c|}{ Factor } & $\begin{array}{l}\text { The compound } \\
\text { model of unsafe } \\
\text { behavior }\end{array}$ & $\begin{array}{l}\text { Not looking at the } \\
\text { traffic before } \\
\text { crossing }\end{array}$ & $\begin{array}{l}\text { Not looking at the } \\
\text { traffic while } \\
\text { crossing }\end{array}$ & $\begin{array}{l}\text { Not walking at the } \\
\text { marked pedestrian } \\
\text { crossings }\end{array}$ \\
\hline \multicolumn{2}{|c|}{ Gender } & $2.488(1.605-3.856)$ & $1.531(0.90-2.444)$ & $2.250(1.393-3.633)$ & $1.419(0.887-2.270)$ \\
\hline \multirow{4}{*}{ Age } & $18-24$ & $\begin{array}{c}2.881(1.007-8.244) \\
p=0 . \cdot 49\end{array}$ & $\begin{array}{c}2.921(0.958-8.909) \\
P=0.060\end{array}$ & $\begin{array}{c}0.879(0.307-2.521) \\
P=0.811\end{array}$ & $\begin{array}{c}0.657(0.196-2.199) \\
P=0.496\end{array}$ \\
\hline & $25-44$ & $\begin{array}{c}2.345(0.898-6.125) \\
P=0.082\end{array}$ & $\begin{array}{c}2.104(0.763-5.799) \\
P=0.151\end{array}$ & $\begin{array}{c}0.805(0.313-2.069) \\
P=0.652\end{array}$ & $\begin{array}{c}1.249(0.447-3.493) \\
P=0.671\end{array}$ \\
\hline & $45-64$ & $\begin{array}{c}1.979(0.715-5.480) \\
P=0.189\end{array}$ & $\begin{array}{c}1.618(0.547-4.788) \\
P=0.385\end{array}$ & $\begin{array}{c}0.915(0.331-2.526) \\
P=0.863\end{array}$ & $\begin{array}{c}1.675(0.569-4.930) \\
P=0.349\end{array}$ \\
\hline & $64<$ & $\begin{array}{c}2.308(0.472- \\
11.278) \\
P=0.301\end{array}$ & $\begin{array}{c}0.636(0.58-7.018) \\
P=0.712\end{array}$ & $\begin{array}{c}0.939(0.144-6.109) \\
P=0.948\end{array}$ & $\begin{array}{c}3.511(0.735-16.765) \\
P=0.115\end{array}$ \\
\hline \multirow{3}{*}{$\begin{array}{l}\text { Walking } \\
\text { conditi } \\
\text { ons }\end{array}$} & $\begin{array}{l}\text { Talking } \\
\text { on the } \\
\text { phone }\end{array}$ & $\begin{array}{c}23.140(11.584- \\
46.223) \\
P<0.001\end{array}$ & $\begin{array}{c}14.577(8.581- \\
24.763) \\
P<0.001\end{array}$ & $\begin{array}{c}14.790(8.664- \\
25.249) \\
P<0.001\end{array}$ & $\begin{array}{c}3.110(1.847-5.237) \\
P<0.001\end{array}$ \\
\hline & $\begin{array}{l}\text { Texting or } \\
\text { viewing } \\
\text { content } \\
\text { on } \\
\text { mobile } \\
\text { phones }\end{array}$ & $\begin{array}{c}15.200(6.763- \\
34.163) \\
P<0.001\end{array}$ & $\begin{array}{c}17.615(8.673- \\
35.780) \\
P<0.001\end{array}$ & $\begin{array}{c}17.671(8.809- \\
35.446) \\
P<0.001\end{array}$ & $\begin{array}{c}2.309(1.133-4.705) \\
P=0.21\end{array}$ \\
\hline & Listening & $\begin{array}{c}0.687(0.182-2.586) \\
P=0.076\end{array}$ & $\begin{array}{c}0.414(0.052-3.272) \\
P=0.403\end{array}$ & $\begin{array}{c}2.086(0.545-7.981) \\
P=0.283\end{array}$ & $\begin{array}{c}0.000 \\
P=0.999\end{array}$ \\
\hline
\end{tabular}

The final model of the prediction of not looking at the traffic before passing from the intersection has had a significantly stronger predictive power than the null model, $t(X 2=174.646 ; \mathrm{df}=8 ; \mathrm{p}<0.001$; pseudo $\mathrm{R} 2 \mathrm{~N}=0.402)$. Predictive parameters included gender, age, and mobile-phone behavior.

Being female had no significant effect on not looking at the traffic before crossing the intersection $(p=$ 0.074 ). Individuals within different age ranges of 18$24,25-44,45-64$, and > 65 had a higher or lower chance of not looking at the traffic prior to crossing the intersection than those who were $<18$ (the reference group) ( $p>0.05$ ). In addition, mobile phone users had a 14.6-time higher chance of not looking at the traffic than the non-mobile phone users $(p<0.001)$. In the meantime, those involved in text messaging or looking at the mobile phone details had a 17.7-time higher chance of not looking at the traffic before crossing the intersection $(p$ $<0.001$ ). Moreover, listening to music had no significant effect on not looking at the traffic before crossing the signalized intersection ( $p=0.403)$.

To predict not looking at the traffic while crossing the intersection, a model was formed by means of predicting parameters, such as gender, age, and mobile-phone use behavior. The power of the final model was more significant than that of the null model $(X 2=162.322 ; \mathrm{df}=8 ; \mathrm{p}<0.001$; pseudo R2N $=0.385)$.

Women had a significantly higher chance (2.2-fold) of not looking at the traffic while crossing the intersection than men $(p=0.001)$. In contrast, the factor of age did not affect significantly the person's chance of not looking at the traffic when crossing the intersection, compared to the reference group (> 18) ( $p>$ 0.05). Those engaged in SMS conversations or looking at their mobile phone screen and those talking on mobile phones had a significantly higher chance of not looking at the traffic while crossing the intersections, 17.7 and 14.8 times, respectively $(p<0.001)$, than those who did not use their mobile phones. In addition, people who were listening to music did not have a higher chance of not looking at the traffic than those who were not using mobile phones $(p=0.283)$.

Unlike previous models, the ultimate model for not crossing at the marked pedestrian crossings had no significantly higher predictive power than the null model (X2 = 162.322; df = 8; $p>0.05$; pseudo R2N $=0.099$ ).

\section{Discussion}

Using mobile phones has a direct correlation with the incidence of unsafe behavior by pedestrians [7, $25,26]$. According to the results, mobile-phone use affected pedestrian precautionary behavior. Women were more probable to show unsafe behavior when crossing intersections than men, with this finding having been in line with earlier studies $[15,17,19]$. Thompson et al (2013) found out that females were twice as likely to exhibit at least one case of unsafe crossing behavior than 
their male counterparts (19). Thompson et al (2013) reported that women were more likely to be aware of traffic lights and other passing pedestrians while crossing the street, but men were more focused on looking at vehicles before and at the time of crossing the street (19). In the study by Hatfield \& Murphy (2007), they concluded that caution behavior was less common in men than in women, with this difference having been significant at signalized intersections for some passing behaviors, such as crossing the pedestrian signal, looking at the traffic while crossing, completing crossing at the marked pedestrian crossing, and conflict experiences (17). A large number of studies also indicate that men tend to show more risky behavior than women (7, $24,26,27)$. Antic et al (2016) reported that men had a 4.1-time higher chance of showing at least one case of unsafe behavior when crossing the street than women (15). However, no significant difference was found between the times and places selected for data collection.

The results of the present study showed that those talking on mobile phones or involved in text messaging and mobile internet were more likely to show unsafe behavior when crossing the signalized intersections. In another study by Hatfield \& Murphy (2007), similar results were obtained. In addition, the interesting result of the present study was that unlike mobile-phone conversations and SMS conversations that distracted pedestrians, listening to music boosted their caution while crossing the signalized intersections (17). In this research, people listening to music while crossing the intersection were less likely to display unsafe behavior than those who did not use mobile phones. This result was also in line with that of previous studies (1, 28-31). In the same vein, Walker et al (2012) concluded that unlike talking on a mobile phone that reduced caution behavior, the use of a personal music player (PMD) did not affect pedestrians' caution behavior. According to another study, people using PMD were at the same level of caution or higher when crossing the street (32). The distraction caused by talking on a mobile phone differs from the one caused by listening to music; listening to music imposes a structural or physical limitation on the pedestrian rather than attentional distraction (like talking on a mobile phone) (32). Hyman et al (2010) concluded that those who go alone with no technology, those who listen to music, and those who move in paired groups are over $50 \%$ of the time more likely to see the unicycling clown (13).

In this study, it was observed that the reference group showed less caution behavior than the timematched control group and the demographicmatched control group. A smaller number of people in the mobile-phone group were looking at the traffic before and when crossing the intersection than the two control groups. In addition, fewer mobile-phone users crossed at the marked pedestrian crossing than the control groups. In general, people using mobile phones had a higher chance of exhibiting unsafe behavior than the time-matched and demographic-matched control groups.

These findings were also in line with those of previous studies (15-19). In a study by Hatfield \& Murphy (2007), it was shown that in terms of cognitive distraction, men and women talking on mobile phones were less likely to behave safely when crossing signalized intersections than control groups, which affected their safety (17). Likewise, in the field of Simulation Observation studies, the results of the present study were confirmed by those of past ones $(33,34)$. Neider et al (2010) reported that pedestrians had the lower chance of proper responding and recognizing while talking on mobile phones and crossing the street (34).

According to the results of this study, both talking on mobile phones and texting distract pedestrians, but these acts as well as listening to music require different cognitive abilities that affect pedestrians' physical and visual distraction. For pedestrians, getting engaged in a mobile phone call may disrupt the auditory mechanism and prevent them from detecting the approach of a vehicle (auditory distraction). While there are many passenger vehicles that interfere with talking and texting on mobile phones, silent vehicles, such as pedal vehicles (bicycles), produce no noise and increase the risk of hitting pedestrians (17).

In this study, it was found out that while taking some steps for the secure crossing at signalized intersections, such as looking at the traffic before and when passing, interfering with text messaging could have a higher impact on distracting pedestrians than talking on mobile phones. Text messaging could lead to showing more unsafe behavior, being a result of a more cognitive and visual distraction. Empirically, visual distractions have the greatest impact on cognitive processes, including memory, visual search, alertness, and word recognition (35). The logical conclusion for this fact is that texting requires a long and frequent look at the mobile phone screen, which results in a more limited sight field (just looking at the mobile phone screen); as a result, pedestrians engaged in it disregard the traffic. This finding has been consistent with earlier studies (19). In fact, when pedestrians had to cross signalized intersections within the allotted time, the presence of the risk made more sense. Pedestrians talking on their mobile phones passing pedestrian lines had a lower chance of passing pedestrian crossings safely than 
others. This is probably due to the fact that when using mobile phones, after hanging up the phone, the user experienced a constant distraction, while when involved in text messaging, pedestrians had the time to stop moving in any possible points to control their direction (15). Researchers have shown that pedestrians talking on a mobile phone are involved in a cognitive distraction that reduces their awareness of the surrounding environment $(2$, 30, 36-40). In addition, the cognitive distraction can lead to slower walking and being placed in hazardous conditions (41) because pedestrians walking more slowly are at a more serious risk (19). This is the case particularly when pedestrians have to cross the street within the designated time at signalized intersections, where this risk is felt more. Like past studies, the present one had some limitations. Firstly, there were only three intersections for recording the pedestrians' crossing behavior. To improve the quality of the results, it is recommended to consider more intersections in future research. In addition, hiring a larger number of experienced observers will contribute to improving the findings. None of the intersections in the city of Gorgan was equipped with pedestrian signals; hence, the pedestrians' reactions under the influence of using mobile phones in obeying or disregarding traffic lights at pedestrian crossings remained unresolved. It is recommended that all behaviors of pedestrians crossing signalized intersections be covered in subsequent studies.

The strength of this study is the fact that the unsafe behavior of pedestrians using mobile phones was compared comprehensively with that of those who did not use mobile phones. In addition, the type and percentage of mobile phone users and the details of their precaution behavior were observed and recorded in three different socioeconomic urban areas (low, medium, and high) within three time periods (in the morning, at noon, and in the afternoon). Besides, a large number of parameters, such as gender, age, and mobile phone use, affecting all unsafe behaviors of the pedestrians crossing the signalized intersections were analyzed. In the end, a thorough comparison was made between the unsafe behaviors in pairs to examine the correlation between them.

\section{Conclusion}

Today, the number of mobile-phone users is increasing along with the great variety and number of electronic devices throughout the world. One of the problems encountered by many societies, especially in Iran, is the rising rate of fatalities, which is due to pedestrians being distracted and their inattention to the route. Using a mobile phone is from among the factors distracting pedestrians, especially while crossing intersections, which often threatens their safety. The results of the present study showed that people using mobile phones display more dangerous behaviors when crossing signalized intersections than time-matched and demographic-matched control groups. In fact, the behavior exhibited when using a mobile phone is important. The present study showed that talking on a mobile phone had the highest impact on the state of inattention and carelessness among pedestrians, thereby putting their safety at risk. However, unlike talking on mobile phones, listening to music had the least impact on the pedestrians' inattention, and even in some cases, it could increase their chance of showing safe behavior while crossing the intersections. Under similar conditions, females showed less inattention than males. The results of this study are also useful in providing pedestrians with civic educational and cultural programs on the possible risks of using mobile phones, especially when crossing the street, in the form of informational campaigns or through education at schools and other educational centers.

\section{Acknowledgement}

This research was supported by Golestan University, Gorgan, Iran. The authors would like to thank the reviewers of this paper for their valuable corrections.

Conflict of interest: None declared.

\section{References}

1. Appel M, Krisch N, Stein JPh, Weber S. Smartphone zombies! Pedestrians' distracted walking as a function of their fear of missing out. J Environ 2019. doi:10.1016/j.jenvp.2019.04.003.

2. Stavrinos D, Pope CN, Shen J, Schwebel DC. Distracted Walking, Bicycling, and Driving: Systematic Review and Meta-Analysis of Mobile Technology and Youth Crash Risk. Child Dev 2018; 89(1):118-28.

3. National Highway Traffic Safety Administration. Traffic Safety Facts 2016. Washington, DC, United States; National Highway Traffic Safety Administration; 2016.

4. World Health Organization. Global status report on road safety 2018. Geneva: World Health Organization; 2018. Available from:

https://apps.who.int/iris/bitstream/handle/10665/ 276462/9789241565684-eng.pdf.

5. Newman Dorland WA. Dorland's American Illustrated Medical Dictionary. Am J Nurs 1906; 7(3):226.

6. Greenwood EJ. Benjamin F Miller, Claire Keane, Encyclopedia and Dictionary of Medicine, 
Nursing, and Allied Health, W B Saunders, Philadelphia and Chichester (1983), p. 1670, illus, £7.95. Nurse Educ Today 1983; 3(4):85.

7. Zhou Z, Liu S, Xu W, Pu Z, Zhang Sh, Zhou Y. Impacts of mobile phone distractions on pedestrian crossing behavior at signalized intersections: An observational study in China. Advances in Mechanical Engineering 2019; 11(4). doi:10.1177/1687814019841838.

8. Scopatz RA, Zhou Y. Effect of electronic device use on pedestrian safety: A literature review. Washington, DC, United States; National Highway Traffic Safety Administration; 2016.

9. Williamson A, Lennon A. Pedestrian selfreported exposure to distraction by smart phones while walking and crossing the road. Paper presented at: The Australasian Road Safety Conference; 2015 Oct 14-16; Gold Coast, Australia.

10. National Highway Traffic Safety Administration. Traffic Safety Facts Research Note: Distracted Driving 2014. Washington, DC, United States: National Highway Traffic Safety Administration. 2016 Apr. 6 p. Report No.: DOT HS 812260.

11. Hamann C, Dulf D, Baragan-Andrada E, Price M, Peek-Asa C. Contributors to pedestrian distraction and risky behaviours during road crossings in Romania. Inj Prev 2017; 23(6):3706.

12. Nasar JL, Troyer D. Pedestrian injuries due to mobile phone use in public places. Accid Anal Prev 2013; 57:91-5.

13. Hyman Jr IE, Boss SM, Wise BM, McKenzie KE, Caggiano JM. Did you see the unicycling clown? Inattentional blindness while walking and talking on a cell phone. Appl Cogn Psychol 2010; 24(5):597-607.

14. Hyman IE Jr, Sarb BA, Wise-Swanson BM. Failure to see money on a tree: inattentional blindness for objects that guided behavior. Front Psychol 2014; 5:356.

15. Pešic D, Antic B, Glavić D, Milenkovic M. The effects of mobile phone use on pedestrian crossing behaviour at unsignalized intersections - Models for predicting unsafe pedestrians behaviour. Saf Sci 2016; 82:1-8.

16. Bungum TJ, Day C, Henry LJ. The association of distraction and caution displayed by pedestrians at a lighted crosswalk. J Community Health 2005; 30(4):269-79.

17. Hatfield J, Murphy S. The effects of mobile phone use on pedestrian crossing behaviour at signalised and unsignalised intersections. Accid Anal Prev 2007; 39(1):197-205.

18. Nasar J, Hecht P, Wener R. Mobile telephones, distracted attention, and pedestrian safety. Accid Anal Prev 2008; 40(1):69-75.

19. Thompson LL, Rivara FP, Ayyagari RC, Ebel BE. Impact of social and technological distraction on pedestrian crossing behaviour: an observational study. Inj Prev 2013; 19(4):232-7.
20. GSM Association. The Mobile Economy Middle East and North Africa 2017. London, United Kingdom: GSM Association; 2017.

21. Pontius Jr RG, Millones M. Death to Kappa: birth of quantity disagreement and allocation disagreement for accuracy assessment. Int $\mathrm{J}$ Remote Sens 2011; 32(15):4407-29.

22. Brosseau M, Zangenehpour S, Saunier N, Miranda-Moreno $\mathrm{L}$. The impact of waiting time and other factors on dangerous pedestrian crossings and violations at signalized intersections: A case study in Montreal. Transp Res Part F Traffic Psychol Behav 2013; 21:15972.

23. Dunbar $\mathrm{G}$. The relative risk of nearside accidents is high for the youngest and oldest pedestrians. Accid Anal Prev 2012; 45:517-21.

24. Herrero-Fernández D, Maćla-Guerrero $P$, Silvano-Chaparro L, Merino L, Jenchura EC. Risky behavior in young adult pedestrians: Personality determinants, correlates with risk perception, and gender differences. Transp Res Part F Traffic Psychol Behav 2016; 36:14-24.

25. Appel M, Krisch N, Stein JPh, Weber S. Smartphone zombies! Pedestrians' distracted walking as a function of their fear of missing out. J Environ Psychol 2019; doi: 10.1016/j.jenvp.2019.04.003

26. Jiang K, Ling F, Feng Z, Ma C, Kumfer W, Shao $\mathrm{C}$, Wang $\mathrm{K}$. Effects of mobile phone distraction on pedestrians' crossing behavior and visual attention allocation at a signalized intersection: An outdoor experimental study. Accid Anal Prev 2018; $170-7$.

27. Wells HL, McClure LA, Porter BE, Schwebel DC. Distracted Pedestrian Behavior on two Urban College Campuses. J Community Health 2018; 43(1):96-102.

28. Tamuz M, Harrison MI. Improving patient safety in hospitals: Contributions of high-reliability theory and normal accident theory. Health Serv Res 2006; 41 (4 Pt 2):1654-76.

29. Pharo E. Extent of mobile phone use by pedestrians on controlled crossings in central Hobart, Tasmania. J Australas Coll Road Saf 2019; 30(1):14-9.

30. Hill T, Sullman MJM, Stephens AN. Mobile phone involvement, beliefs, and texting while driving in Ukraine. Accid Anal Prev 2019; 125:124-31.

31. Horberry T, Osborne R, Young K. Pedestrian smartphone distraction: Prevalence and potential severity. Transp Res Part F Traffic Psychol Behav 2019; 60:515-23.

32. Walker EJ, Lanthier SN, Risko EF, Kingstone A. The effects of personal music devices on pedestrian behaviour. Saf Sci 2012; 50(1):123-8.

33. Schwebel DC, Stavrinos D, Byington KW, Davis T, O'Neal EE, de Jong D. Distraction and pedestrian safety: how talking on the phone, texting, and listening to music impact crossing the street. Accid Anal Prev 2012; 45:266-71. 
34. Neider MB, McCarley JS, Crowell JA, Kaczmarski H, Kramer AF. Pedestrians, vehicles, and cell phones. Accid Anal Prev 2010; 42(2):589-94.

35. Pammer K, Korrel H, Bell J. Visual distraction increases the detection of an unexpected object in inattentional blindness. Vis Cogn 2014; 22(910):1137-83.

36. Byington KW, Schwebel DC. Effects of mobile Internet use on college student pedestrian injury risk. Accid Anal Prev 2013; 51:78-83.

37. Lamberg EM, Muratori LM. Cell phones change the way we walk. Gait Posture 2012; 35(4):68890.

38. Kardos P, Unoka Z, Pléh C, Soltész P. Your mobile phone indeed means your social network: Priming mobile phone activates relationship related concepts. Comput Human Behav 2018; 88:84-8.

39. Jiang K, Ling F, Feng Z, Ma C, Kumfer W, Shao $C$, et al. Effects of mobile phone distraction on pedestrians' crossing behavior and visual attention allocation at a signalized intersection: An outdoor experimental study. Accid Anal Prev 2018; 115:170-7.

40. Alghnam S, Alrowaily M, Alkelya M, Alsaif A, Almoaiqel $F$, Aldegheishem $A$. The prevalence of seatbelt and mobile phone use among drivers in Riyadh, Saudi Arabia: An observational study. J Safety Res 2018; 66:33-7.

41. Lennon A, Oviedo-Trespalacios O, Matthews S. Pedestrian self-reported use of smart phones: Positive attitudes and high exposure influence intentions to cross the road while distracted. Accid Anal Prev 2017; 98:338-47. 